\title{
FAKTOR-FAKTOR YANG BERHUBUNGAN DENGAN KEAKTIFAN LANSIA YANG BERKUNJUNG KE POSYANDU LANSIA MAWAR KELURAHAN PARIT LALANG DI WILAYAH KERJA PUSKESMAS MELINTANG KOTA PANGKALPINANG
}

\author{
Tajudin \\ Jurusan Keperawatan, Poltekkes Kemenkes Pangkalpinang \\ Email: tajudin12333@gmail.com
}

\begin{abstract}
Related Factors of Elderly Activeness who Visit to Elderly IHC Mawar, Parit Lalang village, PHC Melintang, Pangkalpinang. Integrated Health Post (IHC) for the elderly is a form of integration of health services for the elderly in the village or villages in Public Health Centre (PHC) working areas. The research objective was to determine the relationship between knowledge, attitude, family support and infrastructure with the liveliness of the elderly who visit to the elderly IHC Mawar, Parit Lalang village, PHC Melintang, Pangkalpinang, 2015. The study was conducted using case control design. The study population numbered were 274 people. Total case sample were 10 , and 50 people as control.The survey results revealed that there was relationship between knowledge $(\mathrm{p}=0.017$ and $\mathrm{OR}=9.75)$, attitude $(\mathrm{p}=0.014$ and $\mathrm{OR}=10.56)$, family support $(\mathrm{p}=0.013$ and $\mathrm{OR}=11.45)$ and infrastructure $(\mathrm{p}=0.033$ and $\mathrm{OR}=9)$ with the liveliness of the elderly who visit to elderly IHC Mawar, Parit Lalang village, PHC Melintang, Pangkalpinang, 2015.
\end{abstract}

Keywords: Elderly activeness, IHC for the elderly

\begin{abstract}
Abstrak: Faktor-Faktor yang Berhubungan dengan Keaktifan Lansia yang Berkunjung ke Posyandu Lansia Mawar Kelurahan Parit Lalang di Wilayah Kerja Puskesmas Melintang Kota Pangkalpinang. Posyandu lanjut usia adalah suatu bentuk keterpaduan pelayanan kesehatan terhadap lansia di tingkat desa atau kelurahan dalam masing-masing wilayah kerja Puskesmas. Tujuan penelitian adalah untuk mengetahui hubungan antara pengetahuan, sikap, dukungan keluarga dan sarana prasarana dengan keaktifan lansia yang berkunjung ke Posyandu Lansia Mawar Kelurahan Parit Lalang di wilayah kerja Puskesmas Melintang Kota Pangkalpinang Tahun 2015. Penelitian dilakukan dengan menggunakan desain case control. Populasi penelitian berjumlah 274 orang. Untuk memenuhi sampel minimal dalam penelitian ini akan menggunakan perbandingan sampel kasus dan kontrol 1:5. Maka jumlah sampel kasus adalah 10 orang dan kontrol adalah 50 orang. Hasil penelitian diketahui ada hubungan antara pengetahuan $(p=0,017 \&$ $\mathrm{OR}=9,75)$, sikap $(p=0,014 \& \mathrm{OR}=10,56)$, dukungan keluarga $(p=0,013 \& \mathrm{OR}=11,45)$ dan sarana prasarana $(p=0,033 \& \mathrm{OR}=9)$ dengan keaktifan lansia yang berkunjung ke Posyandu Lansia Mawar Kelurahan Parit Lalang di wilayah kerja Puskesmas Melintang Kota Pangkalpinang Tahun 2015.
\end{abstract}

Kata kunci: Keaktifan lansia, Posyandu lansia

Perserikatan Bangsa-Bangsa (PBB) tahun 2011, menyatakan bahwa pada tahun 2000-2005 Umur Harapan Hidup (UHH) manusia yakni 66,4 tahun (dengan persentase populasi lansia tahun 2000 yakni $(7,74 \%)$, angka ini meningkat pada tahun 2045-2050 dimana UHH menjadi 77,6 tahun (dengan persentase populasi lansia tahun 2045 yakni 28,68\%) (Kementerian Kesehatan RI, 2011 diakses pada tanggal 02 Mei 2015).

Badan Pusat Statistik (BPS) melaporkan bahwa terjadi peningkatan umur harapan hidup di Indonesia. Pada tahun 2000 yakni 64,5 tahun (dengan persentase populasi lansia yakni 7,18\%). Dan pada tahun 2010 angka ini meningkat menjadi 69,43 tahun (dengan persentase populasi lansia yakni 7,56\%). Kemudian pada tahun 2011 menjadi 69,65 tahun (dengan persentase lansia yakni 7,58\%) (Kemenkes RI, 2013:20).

Berdasarkan data lansia yang didapat dari Dinas Kesehatan Provinsi Kepulauan Bangka Belitung bahwa tercatat lansia di tahun 2014 sebanyak 91.718 orang dengan jumlah laki-laki sebanyak 54.820 orang dan wanita sebanyak 36.898 orang. Sedangkan lansia yang melakukan kunjungan aktif setiap bulannya tercatat sebanyak 17.583 orang $(19,17 \%)$ dengan jumlah laki-laki sebanyak 6.334 orang $(11,55 \%)$ dan wanita sebanyak $11.249 \quad(30,49 \%)$ (Dinas 
Kesehatan Provinsi Kepulauan Bangka Belitung, 2014:10).

Berdasarkan data lansia yang didapat dari Dinas Kesehatan Kota Pangkalpinang bahwa tercatat lansia di Kota Pangkalpinang tahun 2014 sebanyak 11.599 orang dengan jumlah laki-laki sebanyak 5.530 orang dan wanita sebanyak 6.069 orang. Sedangkan lansia yang melakukan kunjungan aktif setiap bulannya tercatat sebanyak 2.496 orang $(21,5 \%)$ dengan jumlah laki-laki sebanyak 1.413 orang $(25,5 \%)$ dan wanita sebanyak $1.083 \quad(17,8 \%)$ (Dinas Kesehatan Kota Pangkalpinang, 2014:40).

Data lansia yang didapat dari Puskesmas Melintang pada tahun 2014 sebanyak 2.167 orang dengan jumlah laki-laki sebanyak 1.033 orang dan wanita sebanyak 1.134 orang. Sedangkan lansia yang melakukan kunjungan aktif setiap bulannya tercatat sebanyak 276 orang $(12,7 \%)$ dengan jumlah laki-laki sebanyak 163 orang $(15,7 \%)$ dan wanita sebanyak 113 $(9,96 \%)$. Sedangkan data untuk masing-masing Posyandu Lansia di kelurahan dapat dilihat tabel dibawah ini : (Puskesmas Melintang, 2014:34).

Peneliti melakukan survey awal terhadap 10 (sepuluh) orang lansia yang aktif melakukan kunjungan ke Posyandu Lansia dari wawancara yang dilakukan dengan menggunakan kuesioner disimpulkan bahwa lansia yang memiliki pengetahuan kurang baik sebanyak 7 orang (70\%), sedangkan lansia yang memiliki sikap kurang baik sebanyak 4 orang $(40 \%)$. Lansia yang tidak memiliki dukungan keluarga untuk datang ke Posyandu Lansia sebanyak 8 orang $(80 \%)$ dan lansia yang menjawab pertanyaan kuesioner tentang kelengkapan sarana dan prasarana Posyandu Lansia sebanyak 8 orang (80\%) menjawab lengkap sarana dan prasarana yang ada di Posyandu Lansia tersebut.

\section{METODE PENELITIAN}

Jenis penelitian ini menggunakan rancangan "Case Control" disebut case control karena pengumpulan data dimulai dari efek atau akibat yang telah terjadi, kemudian dari efek tersebut ditelusuri penyebab atau variabelvariabel yang mempengaruhi akibat tersebut. Penelitian ini bertujuan untuk mengetahui apakah ada hubungan antara variabel-variabel yang akan diteliti dengan keaktifan lansia datang ke Posyandu Lansia sebagai variabel dependen dan faktor resiko sebagai variabel independen (Basuki, 2000:20).

Penelitian dilakukan di Posyandu Lansia Mawar Kelurahan Parit Lalang di wilayah kerja
Puskesmas Melintang Kota Pangkalpinang. Waktu penelitian akan dilaksanakan tanggal 16 Juni- 6 Juli tahun 2015.

Populasi dalam penelitian ini adalah seluruh lansia yang berada di Kelurahan Parit Lalang Posyandu Lansia Mawar wilayah kerja Puskesmas Melintang tahun 2015 berjumlah 274 orang. Sampel kasus adalah lansia yang datang ke Posyandu lansia setiap bulannya dari bulan Januari-April 2015 yang berjumlah 10 orang dan sampel kontrol adalah lansia yang tidak datang ke Posyandu lansia setiap bulannya dari bulan Januari-April 2015 yang berjumlah 264 orang.

Untuk memenuhi sampel minimal dalam penelitian ini akan menggunakan perbandingan sampel kasus dan kontrol 1:5. Maka jumlah sampel kasus adalah 10 orang dan kontrol 50 orang.

Pengumpulan data dalam penelitian ini adalah dengan cara wawancara dan observasi dengan menggunakan kuesioner dan informend consent yang telah disediakan.

\section{HASIL}

\section{A. ANALISIS UNIVARIAT}

\section{Tabel 1. Distribusi Frekuensi Persentase Keaktifan Lansia ke Posyandu Lansia. Pengetahuan Lansia, Sikap Lansia, Dukungan Keluarga, Sarana dan Prasarana}

Karakteritik Kategori Frekuensi Persentase

\begin{tabular}{|c|c|c|c|}
\hline & & (n) & $(\%)$ \\
\hline Keaktifan & Kasus & 10 & 16,7 \\
\hline lansia & Kontrol & 50 & 83,8 \\
\hline Pengetahuan & Baik & 33 & 55,0 \\
\hline lansia & Kurang & 27 & 45,0 \\
\hline \multirow[t]{2}{*}{ Sikap lansia } & Baik & 31 & 51,7 \\
\hline & Kurang & 29 & 48,3 \\
\hline Dukungan & Mendukung & 31 & 51,7 \\
\hline keluarga & Tidak & 29 & 48,3 \\
\hline Sarana dan & Lengkap & 34 & 56,7 \\
\hline prasarana & Tidak & 26 & 43,3 \\
\hline
\end{tabular}

Hasil penelitian keaktifan lansia ke posyandu lansia kasus sebanyak 10 orang $(16,7 \%)$ lebih sedikit dibandingkan dengan kontrol. Pengetahuan yang baik sebanyak 33 orang (55\%), lebih besar dibandingkan dengan responden yang memiliki pengetahuan kurang baik. Sikap lansia yang baik sebanyak 31 orang $(51,7 \%)$, lebih besar dibandingkan dengan responden yang memiliki sikap kurang baik. dukungan keluarga yang mendukung sebanyak 31 orang $(51,7 \%)$, lebih besar dibandingkan 
dengan responden yang tidak mendukung. responden yang menjawab sarana prasarana lengkap sebanyak 34 orang $(56,7 \%)$, lebih besar dibandingkan dengan responden yang menjawab sarana prasarana tidak lengkap.

\section{B. ANALISIS BIVARIAT}

\section{Hubungan Pengetahuan Lansia dengan Keaktifan Lansia ke Posyandu Lansia}

Responden yang mempunyai pengetahuan baik pada kelompok kasus sebanyak 9 orang (90\%) lebih besar dibandingkan responden pada kelompok kontrol. Sedangkan responden dengan pengetahuan kurang baik pada kelompok kasus sebanyak 1 orang (10\%) lebih sedikit dibandingkan responden pada kelompok kontrol.

Berdasarkan hasil uji chi square test hubungan antara pengetahuan lansia dengan keaktifan lansia Ke Posyandu Lansia, didapatkan nilai $p(0,017)<\alpha(0,05)$ sehingga disimpulkan ada hubungan yang bermakna antara pengetahuan lansia dengan keaktifan lansia Ke Posyandu Lansia.

Hasil analisa lebih lanjut didapatkan nilai $O R=9,75(95 \%$ CI : 1,14-82,80), hal ini berarti bahwa responden yang memiliki pengetahuan baik 9,75 kali untuk datang berkunjung ke Posyandu Lansia dibandingkan responden yang memiliki pengetahuan kurang baik.

\section{Hubungan Sikap Lansia dengan Keaktifan Lansia ke Posyandu Lansia}

Responden yang mempunyai sikap baik pada kelompok kasus sebanyak 9 orang (90\%) lebih besar dibandingkan responden pada kelompok kontrol. Sedangkan responden dengan sikap kurang baik pada kelompok kasus sebanyak 1 orang (10\%) lebih sedikit dibandingkan responden pada kelompok kontrol.

Berdasarkan hasil uji chi square test hubungan sikap lansia dengan Keaktifan Lansia Ke Posyandu Lansia, didapatkan nilai $p(0,014)<$ $\alpha(0,05)$ sehingga disimpulkan ada hubungan yang bermakna antara sikap lansia dengan Keaktifan Lansia Ke Posyandu Lansia.

Hasil analisa lebih lanjut didapatkan nilai $\mathrm{OR}=10,56(95 \% \mathrm{CI}: 1,24-89,75)$, hal ini berarti bahwa responden yang memiliki sikap baik 10,56 kali untuk datang berkunjung ke Posyandu Lansia dibandingkan responden yang memiliki sikap kurang baik.

\section{Hubungan Dukungan Keluarga dengan Keaktifan Lansia ke Posyandu Lansia \\ Responden yang keluarganya mendukung} pada kelompok kasus sebanyak 9 orang (90\%) lebih besar dibandingkan responden pada kelompok kontrol. Sedangkan responden yang keluarganya tidak mendukung pada kelompok kasus sebanyak 1 orang (10\%) lebih sedikit dibandingkan responden pada kelompok kontrol.

Berdasarkan hasil uji chi square test hubungan dukungan keluarga dengan Keaktifan Lansia Ke Posyandu Lansia, didapatkan nilai $p$ $(0,013)<\alpha(0,05)$ sehingga disimpulkan ada hubungan yang bermakna antara dukungan keluarga dengan Keaktifan Lansia Ke Posyandu Lansia.

Hasil analisa lebih lanjut didapatkan nilai OR=11,45 (95\% CI: 1,34-97,36), hal ini berarti bahwa responden yang memiliki dukungan keluarga yang mendukung 11,45 kali untuk datang berkunjung ke Posyandu Lansia dibandingkan responden yang tidak memiki dukungan keluarga.

\section{Hubungan Sarana Prasarana dengan Keaktifan Lansia ke Posyandu Lansia}

Responden yang menjawab sarana prasarana lengkap di posyandu lansia pada kelompok kasus sebanyak 9 orang (90\%) lebih besar dibandingkan responden pada kelompok kontrol. Sedangkan responden yang menjawab sarana prasarana tidak lengkap di posyandu lansia pada kelompok kasus sebanyak 1 orang $(10 \%)$ lebih sedikit dibandingkan responden pada kelompok kontrol.

Berdasarkan hasil uji chi square test hubungan sarana prasarana dengan Keaktifan Lansia Ke Posyandu Lansia, didapatkan nilai $p$ $(0,033)<\alpha(0,05)$ sehingga disimpulkan ada hubungan yang bermakna antara sarana prasarana dengan Keaktifan Lansia ke Posyandu Lansia.

Hasil analisa lebih lanjut didapatkan nilai $O R=9(95 \%$ CI: 1,06-76,42), hal ini berarti bahwa dengan adanya sarana prasarana posyandu lansia yang lengkap maka keinginan lansia 9 kali untuk datang berkunjung ke posyandu lansia dibandingkan dengan sarana prasarana posyandu lansia yang tidak lengkap. 
Tabel 2. Distribusi frekuensi persentase Hubungan antara Pengetahuan Lansia dengan Keaktifan Lansia ke Posyandu Lansia

\begin{tabular}{|c|c|c|c|c|c|c|c|c|}
\hline \multirow{3}{*}{$\begin{array}{l}\text { Variabel } \\
\text { penelitian }\end{array}$} & \multirow[t]{3}{*}{ Kategori } & \multicolumn{4}{|c|}{$\begin{array}{c}\text { Keaktifan Lansia ke } \\
\text { Posyandu Lansia }\end{array}$} & \multirow[t]{3}{*}{ Jumlah } & \multirow[t]{3}{*}{$p$} & \multirow{3}{*}{$\begin{array}{c}\text { OR } \\
(95 \% C I)\end{array}$} \\
\hline & & \multicolumn{2}{|c|}{ Kasus } & \multicolumn{2}{|c|}{ Kontrol } & & & \\
\hline & & $\mathbf{n}$ & $\%$ & $\mathbf{n}$ & $\%$ & & & \\
\hline Pengetahuan & Baik & 9 & 90 & 24 & 48 & 33 & 0,017 & $9,75(1,14-82,80)$ \\
\hline lansia & Kurang & 1 & 10 & 26 & 52 & 27 & & \\
\hline \multirow[t]{2}{*}{ Sikap lansia } & Baik & 9 & 90 & 23 & 46 & 32 & 0,014 & $0,56(1,24-89,75)$ \\
\hline & Kurang & 1 & 10 & 27 & 54 & 28 & & \\
\hline Dukungan & Mendukung & 9 & 90 & 22 & 44 & 31 & 0,013 & $11,45(1,34-97,36)$ \\
\hline keluarga & Tidak mendukung & 1 & 10 & 28 & 56 & 29 & & \\
\hline Sarana & Lengkap & 9 & 90 & 25 & 50 & 34 & 0,033 & $9(1,06-76,42)$ \\
\hline prasarana & Tidak lengkap & 1 & 10 & 25 & 50 & 26 & & \\
\hline
\end{tabular}

\section{PEMBAHASAN}

\section{Hubungan Pengetahuan Lansia dengan Keaktifan Lansia ke Posyandu Lansia}

Penelitian ini sejalan dengan penelitian yang dilakukan oleh Winarsih (2011: 69) di Puskesmas Kemensu II Kabupaten Boyolali, menunjukkan bahwa pengetahuan dapat mempengaruhi lansia untuk berkunjung ke posyandu lansia dengan nilai $\mathrm{p}(0,045)$ dan didapatkan bahwa responden yang memiliki pengetahuan baik 4,9 kali ingin berkunjung ke Puskesmas Kemensu II Kabupaten Boyolali dibandingan dengan responden yang memiliki pengetahuan yang buruk.

Dari penelitian yang dilakukan oleh Sari (2013: 78) yang berjudul tingkat pengetahuan lanjut usia terhadap pemanfaatan posyandu lanjut usia di Desa Karang Jati Kalijambe Sergan tahun 2013 mengatakan ada hubungan pengetahuan lanjut usia terhadap pemanfaatan posyandu lanjut usia dengan ditunjukkan oleh kurangnya kunjungan lanjut usia ke posyandu lanjut usia yang ada di Desa Karangjati. Hasil penelitian ini menyebutkan bahwa lansia yang memiliki pengetahuan baik untuk datang ke posyandu lansia sebanyak $5 \mathrm{x}$ dibandingkan dengan lansia yang memiliki pengetahuan tidak baik.

Berdasarkan hasil penelitian maka peneliti berpendapat bahwa lansia pada umumnya dapat membaca untuk meningkatkan pengetahuan mereka akan tetapi mereka sulit menerima pesan, mencerna pesan, dan informasi yang disampaikan tentang Posyandu Lansia. Hal ini dikarenakan karena adanya penurunan fungsi jaringan pada otot, susunan saraf dan jaringan lain-lain sehingga mereka sulit untuk mencerna apa yang disampaikan oleh petugas kesehatan.

\section{Hubungan Sikap Lansia dengan} Keaktifan Lansia ke Posyandu Lansia

Penelitian ini sejalan dengan penelitian yang dilakukan oleh Henniwati (2013) yang berjudul faktor-faktor yang mempengaruhi pemanfaatan pelayanan posyandu lanjut usia di wilayah kerja Puskesmas Kabupaten Aceh Timur. Hasil penelitian menunjukkan bahwa sikap mempengaruhi lanjut usia dalam pemanfaatan pelayanan posyandu lanjut usia di wilayah kerja Puskesmas Kabupaten Aceh Timur. Hasil penelitian ini didapatkan bahwa nilai $p(0,041)$ dan responden yang memiliki sikap yang baik 4,1 kali ingin berkunjung ke posyandu lanjut usia dibandingkan dengan responden yang memiliki sikap yang kurang baik.

Penelitian ini juga pernah dilakukan oleh Sukardianto (2014: 52) hubungan sikap dengan kunjungan lansia untuk datang ke Posyandu Lansia di Kelurahan Tuatunu wilayah kerja Puskesmas Gerunggang tahun 2014 yang menyatakan adanya hubungan yang bermakna antara sikap dengan kunjungan lansia datang ke Posyandu Lansia. Penelitian ini menyimpulkan bahwa sikap yang baik akan berdampak pada kunjungan posyandu lansia dengan nilai $p$ (0,001).

Peneliti berpendapat bahwa sikap setiap lansia dapat mempengaruhi dari keinginan lansia untuk datang ke Posyandu Lansia. Hal ini diperngaruhi oleh kesan paling mendalam pada setiap lansia yang datang melakukan pemeriksaan. Kejadian dan peristiwa yang terjadi secara berulang dan terus-menerus, lama-kelamaan dengan memberikan pengetahuan yang berulang sehingga dapat membentuk sikap yang positif lansia agar dapat menerapkan pola hidup sehat seperti yang dianjurkan oleh petugas kesehatan yanga ada di posyandu lansia. Hal inilah yang kemudian setiap 
lansia akan secara rutin datang ke Posyandu Lansia untuk menjaga kesehatan, mendengarkan penyuluhan kesehatan, penimbangan berat badan pada saat menghadiri kegiatan posyandu lansia, pengukuran tinggi badan dan tekanan darah. Karena dengan datangnya ke Posyandu Lansia setiap lansia bisa memeriksakan kesehatannya dan mengontrolnya apabila terjadi suatu gangguan kesehatan di dalam tubuh.

\section{Hubungan Dukungan Keluarga dengan Keaktifan Lansia ke Posyandu Lansia}

Penelitian ini sejalan dengan penelitian Handayani, (2012:70) tentang hubungan dukungan keluarga dengan kepatuhan usia lanjut dalam mengikuti posyandu lanjut usia di posyandu lanjut usia Jetis Desa Krajan Kecamatan Weru Kabupaten Sukoharjo menunjukkan bahwa dari 100 responden usia lanjut, 60 responden mempunyai dukungan keluarga rendah dan sebagian besar responden mempunyai kategori tidak patuh dalam mengikuti posyandu usia lanjut. Hal ini dikarenakan usia lanjut yang tidak di ingatkan jadwal posyandu oleh keluarganya karena keluarga sibuk bekerja dan keluarga tidak memberi semangat dan perhatian pada usia lanjut dalam menghadiri posyandu usia lanjut.

Peneliti berpendapat bahwa dukungan dari keluarga dapat berupa kesanggupan keluarga untuk mengantar maupun mengingatkan lansia untuk datang ke posyandu lansia. Dukungan keluarga yang baik dengan memberikan perhatian dan motivasi akan membuat lansia datang ke posyandu juga semakin kuat sehingga lansia bisa aktif datang ke posyandu lansia. Dengan kurangnya dukungan keluarga dari setiap anggota keluarga untuk mengajak orang tuanya berkunjung ke Posyandu Lansia maka para lansia tersebut akan malas untuk melakukan pemeriksaan karena kurangnya perhatian dan dorongan dari anggota keluarga.

\section{Hubungan Sarana Prasarana dengan Keaktifan Lansia ke Posyandu Lansia}

Penelitian ini sejalan dengan penelitian Mamik Endang (2013:73) tentang hubungan antara sarana prasarana dengan keaktifan lansia datang ke posyandu lansia di Dusun Kudu Desa
Kudu Banjar Kecamatan Kudu Kabupaten Jombang Tahun 2013. Hasil penelitian ini didapatkan nilai $p(0,028)$ dengan nilai $\mathrm{OR}$ adalah 4,1 kali yang menunjukkan bahwa sarana prasarana yang lengkap akan membuat 4,1 kali lansia ingin datang ke posyandu lansia di Dusun Kudu.

Peneliti berpendapat bahwa setiap sarana dan prasarana yang dibutuhkan pada posyandu lansia seperti gedung, ruangan/tempat terbuka, meja dan kursi, alat tulis, buku pencatatan kegiatan, timbangan dewasa, meteran pengukur tinggi badan, stetoskop, tensimeter, peralatan laboratorium sederhana, thermometer, KMS (Kartu Menuju Sehat). Untuk di wilayah kerja Puskesmas Melintang Kota Pangkalpinang Tahun 2015 sudah memiliki peralatan yang lengkap. Sehingga pasien lansia akan tertarik untuk melakukan pemeriksaan kesehatan.

\section{SIMPULAN}

Kunjungan keaktifan lansia ke posyandu lansia kasus sebanyak 10 orang $(16,7 \%)$ lebih sedikit dibandingkan dengan kontrol. Berdasarkan hasil analisa bivariat menunjukkan bahwa ada hubungan yang bermakna antara Pengetahuan lansia $(p=0,017)$, Sikap lansia $(p=$ $0,014)$, Dukungan Keluarga $(p=0,013)$ dan Sarana Prasarana $(p=0,033)$ dengan Keaktifan Lansia Ke Posyandu Lansia di Posyandu Lansia Mawar Kelurahan Parit Lalang di wilayah kerja Puskesmas Melintang Kota Pangkalpinang Tahun 2015. Faktor yang paling berpengaruh adalah dukungan keluarga sdengan nilai $\mathrm{OR}=11,45$ (95\% CI : 1,06-76,42).

\section{SARAN}

Perlunya pemberian penyuluhan kepada setiap lansia agar mereka mengerti pentingnya datang ke Posyandu Lansia untuk memeriksakan kesehatannya. Dengan demikian setiap lansia yang melakukan kunjungan agar dideteksi lebih awal mengenai penyakit yang diderita oleh lansia.

\section{DAFTAR PUSTAKA}

Basuki. 2000. Metodologi Penelitian Kesehatan. Jakarta: Rineka Cipta.

Dinas Kesehatan Provinsi Kepulauan Bangka Belitung. 2014. Profil Dinas Kesehatan
Provinsi Kepualauan Bangka Belitung Tahun 2014. Pangkalpinang: Dinas Kesehatan Provinsi Kepulauan Bangka Belitung. 
Dinas Kesehatan Kota Pangkalpinang. 2014. Profil Dinas Kesehatan Kota Pangkalpinang Tahun 2014. Pangkalpinang: Dinas Kesehatan Kota Pangkalpinang.

Handayani. 2012. Gambaran Dukungan Keluarga Terhadap Pemanfaatan Posyandu Lansia di Kelurahan Karasak Kota Bandung. Skripsi. Bandung: Universitas Padjajaran.

Henniwati. 2013. Faktor-Faktor yang Mempengaruhi Pemanfaatan Pelayanan Posyandu Lanjut Usia di Wilayah Kerja Puskesmas Kabupaten Aceh Timur. Tesis. Tidak diterbitkan. Sekolah Pascasarjana. Universitas Sumatra Utara.

Kementerian Kesehatan RI. 2011. Pentingnya Umur Harapan Hidup Manusia. www.umurharapanhidupmanusia.org.natio nal.html (Diakses pada tanggal 02 Mei 2015).

Kementerian Kesehatan RI. 2013. Pedoman Pengelolaan Kegiatan Kesehatan di Kelompok Lanjut Usia. Jakarta: Direktorat Bina Kesehatan Komunitas.

Mamik Endang. 2013. Hubungan antara Pengetahuan dengan Keaktifan Lansia
Datang ke Posyandu Lansia di Dusun Kudu Desa Kudu Banjar Kecamatan Kudu Kabupaten Jombang Tahun 2013. Skripsi. Jombang: STIKES Pemkab Jombang.

Puskesmas Melintang. 2014. Profil Puskesmas Melintang Kota Pangkalpinang Tahun 2014. Pangkalpinang: Puskesmas Melintang.

Sari. 2013. Pengaruh Tingkat Pengetahuan Lanjut Usia Terhadap Pemanfaatan Posyandu Lanjut Usia di Desa Karangjati Kalijambe Sragen Tahun 2013. Skripsi. Jawa Tengah: Fakultas Kesehatan. Universitas Muhammadiyah Surakarta.

Sukardianto. 2014. Hubungan Sikap Dengan Kunjungan Lansia untuk Datang ke Posyandu Lansia di Kelurahan Tuatunu Wilayah Kerja Puskesmas Gerunggang Tahun 2014. Skripsi. Pangkalpinang. Stikes Abdi Nusa Pangkalpinang.

Winarsih. 2011. Faktor-faktor yang Berhubungan dengan Kunjungan Lansia ke Posyandu Lansia di Puskesmas Kemensu II Kabupaten Boyolali. Skripsi. Jawa Tengah. Fakultas Kesehatan. Universitas Boyolali. 